\title{
1,2-Benzisoxazole-3-Acetamidoxime Hydrochloride, a New Psychotropic Agent
}

During the course of pharmacological studies of a series of 3-substituted 1,2-benzisoxazoles with general formula (I), we have found that some compounds show effects on the central nervous system (CNS) in experimental animals. 1,2-Benzisoxazole-3-acetamidoxime hydrochloride (PF257) is one of such compounds with the chemical structure shown by (II).<smiles>[R]c1noc2ccccc12</smiles>

(1)<smiles>NC(Cc1noc2ccccc12)=NO</smiles>

(II)
PF-257 was first found, in routine pharmacological tests with rodents, to possess potent antireserpine activity and several other properties in common with the existing antidepressant drugs ${ }^{1-3}$. Subsequent biochemical and neuropharmacological studies suggested that the effects of PF-257 might be exerted through the mode of action different from those of any known psychotropic drugs including antidepressants.

PF-257 caused no observable behavioral changes in mice and rats at single oral doses smaller than 100 and $300 \mathrm{mg} / \mathrm{kg}$, respectively. At doses larger than $200 \mathrm{mg} / \mathrm{kg}$ in mice, a sedative state with reduced locomotion was observed. In mice and rats, PF-257 was shown to reverse and to prevent reserpine-induced hypothermia and ptosis, in the manner similar to the action of tricyclic antidepressants or monoamine oxidase inhibitors ${ }^{4}$ (MAOI). The potency of its activity was almost comparable to that of imipramine or amitriptyline and less than that of methamphetamine. In addition, PF-257 could prevent the reserpine-induced lowering of the threshold to convulsions induced by electroshock in mice and rats, suggesting the CNS as its site of action.

PF-257 potentiated yohimbine-induced convulsions in mice as did imipramine, MAOIs, and methamphetamine $^{5}$, but failed to affect the pentetrazol-induced convulsions, unlike imipramine and methamphetamine. When given i.v. $(1 \mathrm{mg} / \mathrm{kg})$ to anesthetized cats, it potentiated the contractile responses of the nictitating membrane to i.v. injected adrenaline and tyramine and also the pressor responses elicited by both agents.

At doses below the neurotoxic one $(69.8 \mathrm{mg} / \mathrm{kg}$, i.p.), PF-257 selectively blocked the muricide behavior of rats made aggressive by surgical removal of the olfactory bulbs. Like MAOIs and amantadine, PF-257 potentiated the $\beta$ - $(3,4$-dihydroxyphenyl $)$-L-alanine ( $\mathrm{L}$-DOPA)-induced excitation in mice, but unlike them, it did not increase the toxicity of methamphetamine in grouped mice.

In vitro, even at high concentrations $\left(10^{-6}-10^{-5} \mathrm{~g} / \mathrm{ml}\right)$, PF-257 showed little effect on the contractile responses of guinea-pig ileum to acetylcholine, histamine, or nicotine and rat uterus to 5-hydroxytryptamine (5-HT). It was further shown that PF-257 did not protect mice from cholinomimetic effects of oxotremorine. These results seem to imply that PF-257 has no cholinolytic activity in the CNS.

The effects of PF-257 on the electroencephalogram were rather complex. In gallamine-immobilized cats, PF-257 at doses of $2-5 \mathrm{mg} / \mathrm{kg} \mathrm{i.v}$. caused drowsy patterns with slow waves and high amplitudes in the cortex. At higher dose of $10 \mathrm{mg} / \mathrm{kg}$, it slightly accelerated EEG arousal patterns by reducing the amplitude and increasing the mean frequency in the cortex and by prolonging the time of arousal in the hippocampus. When alteration of the sleep-wakefullness cycle was studied in rats with chronically implanted electrodes throughout $8 \mathrm{~h}$, it caused, at doses of $20-50 \mathrm{mg} / \mathrm{kg}$ i.p., decrease in slow wave sleep and increase in wakefullness.

A single large dose ( $300 \mathrm{mg} / \mathrm{kg}$, orally) or repeated doses (30 $\mathrm{mg} / \mathrm{kg}$, orally) of $\mathrm{PF}-257$ slightly but significantly increased brain noradrenaline (NA) in rats without affecting the contents of dopamine (DA) and 5-HT. This action of PF-257 is reminiscent of that of MAOIs. However, it was proved both in vitro and in vivo that PF-257 did not inhibit monoamine oxidase in the brain and liver. It was also shown that PF-257 lacked the activity to inhibit catechol- $O$-methyltransferase in vivo as well as in vitro.

In spite of lacking the property to inhibit monoaminemetabolizing enzymes, $\mathrm{PF}-257$ could prevent and reverse the decrease of brain monoamines caused by reserpine.

In the in vitro experiment where the effect on ${ }^{3} \mathrm{H}-\mathrm{NA}$ uptake $^{6}$ by rat brain nerve endings was examined, PF-257 was shown to be devoid of the capacity to inhibit NA uptake, in contrast to the potent inhibition by methamphetamine, imipramine, chlorpromazine, and haloperidol.

In accordance with the result of L-DOPA potentiation test in mice, the administration of PF-257 to rats in combination with L-DOPA enhanced the increase in brain DA caused by the amino acid alone. The potentiation by PF-257 appears not to be due to the inhibition of peripheral L-DOPA decarboxylase ${ }^{7}$, since it is not an inhibitor of amino acid decarboxylase.

One of the interesting biochemical properties of PF-257 seems to be its effect on catecholamine turnover in the brain. In rats injected i.p. with DL- $\alpha$-methyl-p-tyrosine to block catecholamine biosynthesis ${ }^{8}, \mathrm{PF}-257$ reduced the rate of disappearance of endogenous NA and DA in the brain at oral doses over $30 \mathrm{mg} / \mathrm{kg}$, suggesting its property to retard the catecholamine turnover.

Thus, PF-257 is a compound having a novel profile, different from those of the existing psychotropic drugs in its pharmacological properties and underlying mode of action. It seems, therefore, worthwhile to study the clinical efficacy of this compound in the treatment of psychiatric disorders in man.

Résumé. Le PF-257 ou chlorhydrate de benzisoxazole1,2 acétamidoxime- 3 produit des effets variés sur le système nerveux central des animaux. Le profil pharmacologique et l'action fondamentale de cet agent paraissent nouveaux, comparés à ceux des psychotropiques actuels.

M. ShimizU, K. Yoshida, T. Karasawa, M. Masuda, M. Oka, T. Ito, C. KameI, M. Hori, Y. SOHJI and K. Furukawa

Research Laboratories, Dainippon Pharmacentical Co., Ltd., Suita, Osaka, 564 (Japan), 2 October 1973.

I S. Garattini and L. J. Valzeli, J. Pharm. Pharmac. 14, 509 (1962).

2 F. Sulser, J. WAtts and B. B. Brodie, Ann. N.Y. Acad. Sci. 96 , 279 (1962).

3 K. Vorth and F. Herr, Archs int. Pharmacodyn. 182, 318 (1969).

4 P.S. J. Spencer, in Antidepressant Drugs (Eds. S. GaratTini and M. N. G. Dukrs; Excepta Medica, Amsterdam 1966), p. 194.

5 R. M. Quinton, Br. J. Pharmac. 21, 51 (1963).

6 S. H. SNyder and J. T. Coyle, J. Pharmac. exp. Ther. 165, 78 (1969).

7 G. Bartholini, H. M. Bates, W. P. Burkard and A. Pletscher, Nature, Lond. 215, 852 (1967).

a B. B. Brodie, E. Costa, A. Dlabac, N. H. Neff and H. H. SmookLER, J. Pharmac. exp. Ther. 754, 493 (1966). 